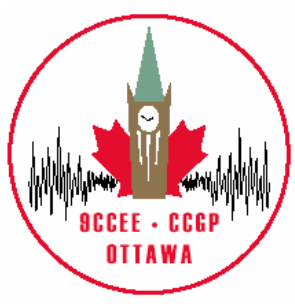

Ninth Canadian Conference on Earthquake Engineering Ottawa, Ontario, Canada 26-29 June 2007

\title{
A SIMPLIFIED METHOD FOR SEISMIC ANALYSIS OF ROOFTOP TELECOMMUNICATION TOWERS
}

\author{
R. Assi ${ }^{1}$ and G. McClure ${ }^{2}$
}

\begin{abstract}
A simplified method for the estimation of seismic forces at the base of self-supporting telecommunication towers mounted on building rooftops is presented in this paper. While some codes and standards propose simplified methods for the evaluation of base shear forces for towers founded on ground, no method yet exists for the evaluation of base overturning moments, either on ground or on buildings rooftops. The proposed method requires the prediction of input seismic acceleration at the building-tower interface, the definition of an acceleration profile along the building-mounted tower, and finally the mass distribution of the tower along its height. The method was developed on the basis of detailed dynamic analysis of three self-supporting steel lattice towers assumed to be mounted separately on three existing buildings. It was found that the proposed method generally yields conservative results. The method is proposed as a simplified design check: if this design check indicates that seismic loads do govern the tower design, a more detailed dynamic analysis of the tower-building system is recommended.
\end{abstract}

\section{Introduction}

The prediction of realistic seismic forces at the base of telecommunication towers is necessary for an adequate seismic design. Modern codes and standards have recently addressed the seismic analysis of self-supporting telecommunication towers on building rooftops by either proposing a simplified method for the estimation of seismic base shear forces (IBC 2000, NRC/IRC 2005, TIA/EIA 2005), or at least by acknowledging the importance of the problem (CSA S37 2001, AS 3995 1994). In addition, the base overturning moment induced at the legs of these towers is not addressed yet in codes and standards. In the authors' opinion based on detailed dynamic analyses (Assi 2006), the simplified approaches in codes and standards are often inappropriate, since most telecommunication towers are acceleration-sensitive components with distributed mass and stiffness. This paper presents a simplified, accurate, and yet easy to implement static method for the seismic analysis of self-supporting telecommunication towers mounted on building rooftops. The purpose of this method is to provide tower designers a quick tool to evaluate the seismic forces on telecommunication towers mounted on building rooftops, namely base shear force and overturning moment, while avoiding the detailed modeling of the supporting buildings. If this simplified design check indicates that seismic loads do govern the tower design, a more detailed dynamic analysis of the tower-building system is recommended.

\footnotetext{
${ }^{1}$ SNC-Lavalin Group Inc., 620 René-Lévesque West, Montréal, QC, H3B 1N7, rola.assi@snclavalin.com

${ }^{2}$ Associate Professor, Department of Civil Engineering and Applied Mechanics, McGill University, 817 Sherbrooke Street West, Montréal, QC, H3A 2K6, ghyslaine.mcclure@mcgill.ca
} 


\section{Analysis of building-tower combinations}

The proposed method is based on numerical simulations using truncated modal superposition analysis to determine the maximum forces in the tower legs at the building-tower interface. 3-D finite element models for 3 towers assumed to be mounted on each of 3 buildings were generated in Sap 2000 (Wilson and Habibullah 2003), resulting in 9 building-tower combinations. Elastic time-history modal superposition analysis was performed for each building-tower combination. The 20 lowest frequency modes were considered and a uniform viscous damping ratio of $3 \%$ critical was used for each mode. Two of the modeled buildings are located in Taiwan and the third one is located in downtown Montréal. The models of the Taiwanese buildings were calibrated using recorded floor accelerations during the 1999 Chi Chi earthquake and the fundamental periods extracted by system identification techniques using the same accelerograms (Assi 2006).

\section{Earthquake records}

The finite element model of each of the 9 building-tower combinations was subjected to two sets of earthquake records applied separately in both principal horizontal directions (U1 and U2) of the buildings. The first set includes 44 historical records resulting from 23 events and classified into three categories according to the ratio of the peak ground horizontal acceleration (PGA) to the peak ground horizontal velocity $(\mathrm{PGV}),(\mathrm{a} / \mathrm{v})$, including 14 records with high $\mathrm{a} / \mathrm{v}$ ratio labeled $\mathrm{H}, 15$ records with medium $\mathrm{a} / \mathrm{v}$ ratio labeled $\mathrm{M}$, and 15 records with low a/v ratio labeled $\mathrm{L}$. More details about these earthquake records can be found in Tso et al. (1992). The second set includes three series, each including 10 synthetic timehistories compatible with the target Uniform Hazard Spectra for Montréal, corresponding to probabilities of exceedance of $2 \%, 10 \%$, and $50 \%$ in 50 years, respectively, and labeled as $2 \%, 10 \%$, and $50 \%$, respectively. These time histories were generated based on the stochastic approach presented by Atkinson and Beresnev (1998). A total of 15 magnitude-distance (M-R) scenarios were applied to cover the frequency range of interest. Due to the randomness of the generated records, two acceleration timehistories were used for each M-R scenario.

\section{Characteristics of the buildings used in the study}

The isometric views of the three studied buildings and their corresponding detailed 3-D finite element mesh models are illustrated in Figs. 1 to 3 . Table 1 summarizes the geometric properties and dynamic characteristics of the building models. Rigid floor slabs were assumed while the columns, beams and walls were modeled in details. The mass of non-structural components and finishing was distributed to columns and walls according to their tributary area.

Table 1. Geometric properties and natural periods of the modeled buildings.

\begin{tabular}{|c|c|c|c|c|c|c|c|}
\hline \multirow{2}{*}{$\begin{array}{l}\text { Building } \\
\text { ID }\end{array}$} & \multirow[b]{2}{*}{ Location } & \multirow[b]{2}{*}{ Use } & \multirow[b]{2}{*}{ LLRS $^{*}$} & \multirow[b]{2}{*}{ Height (m) } & \multicolumn{3}{|c|}{ Natural periods } \\
\hline & & & & & $\begin{array}{c}\mathrm{T}_{1}(\mathrm{~s}) \\
\text { (sway) }\end{array}$ & $\begin{array}{l}\mathrm{T}_{2}(\mathrm{~s}) \\
\text { (sway) }\end{array}$ & $\begin{array}{c}\mathrm{T}_{3}(\mathrm{~s}) \\
\text { (torsion) }\end{array}$ \\
\hline CHYBA9 & Tainan & Telecom & Dual & 20 & 0.30 & 0.26 & 0.17 \\
\hline CHYBA4 & Jia-Yi & Hospital & Frame & 24.2 & 0.41 & 0.31 & 0.23 \\
\hline $\begin{array}{c}2020 \\
\text { University }\end{array}$ & Montréal & Office & Frame & 115.2 & 2.0 & 1.9 & 1.36 \\
\hline
\end{tabular}

*LLRS refers to the lateral load resisting system

*Frame refers to a reinforced concrete frame system

${ }^{*}$ Dual refers to a moment-wall system 

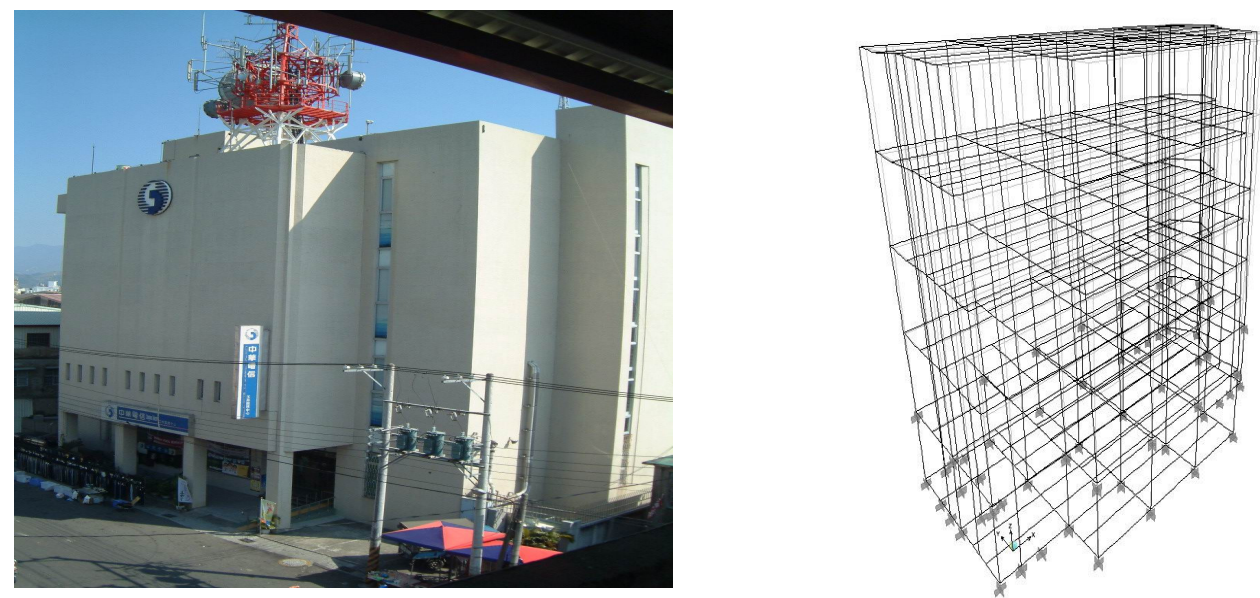

Figure 1. Isometric view and finite element mesh model of the CHYBA9 building.
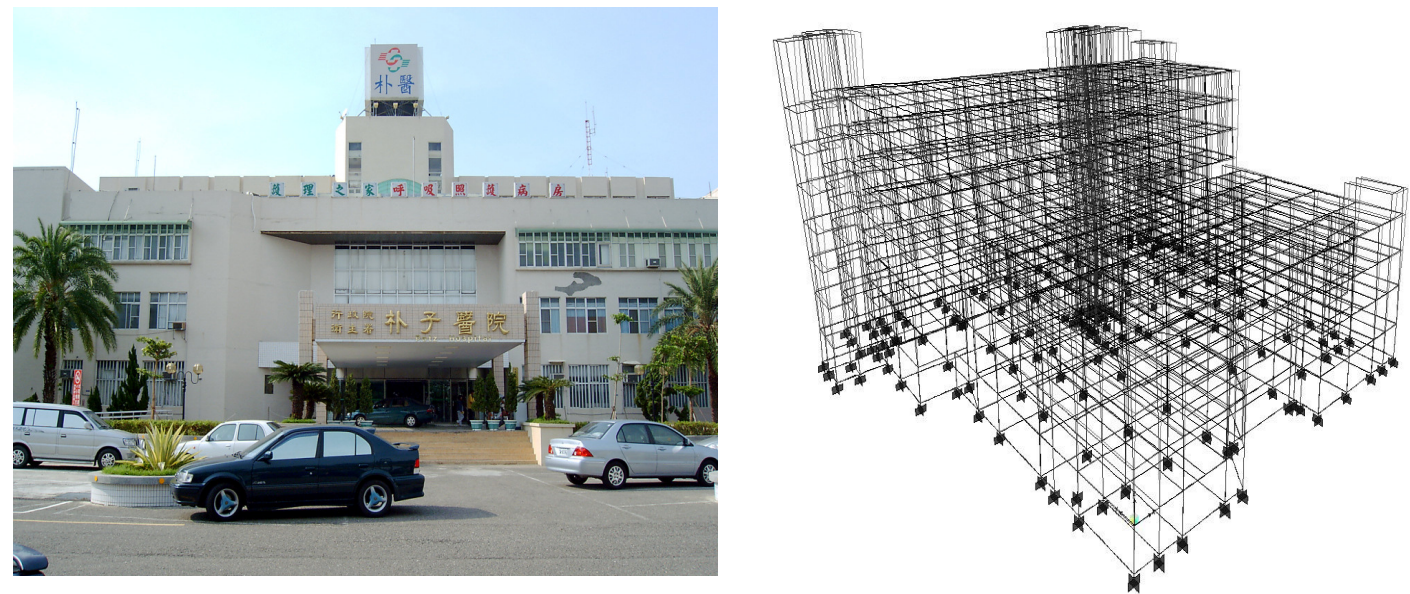

Figure 2. Isometric view and finite element mesh model of the CHYBA4 building.
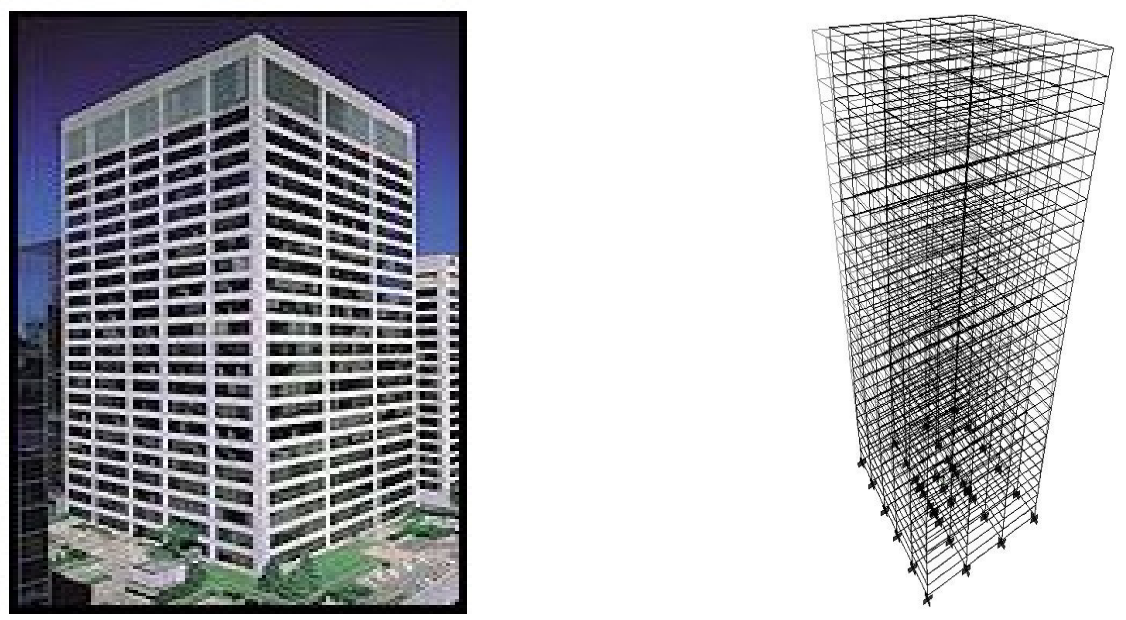

Figure 3. Isometric view and finite element mesh model of the 2020 University building. 


\section{Characteristics of the telecommunication towers used in the study}

Three typical medium-height towers were studied. Fig. 4 illustrates the finite element meshes of the tower models and Table 2 summarizes their geometric properties and dynamic characteristics. The tower models were assumed rigidly connected to the roof of the building models. An example of such a connection is illustrated in Fig. 5 for the CHYBA9 telecom building in Tainan City.

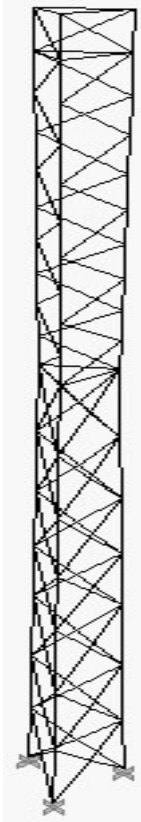

a) TC1

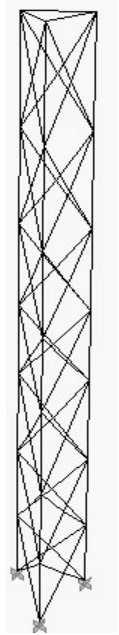

b) TC2

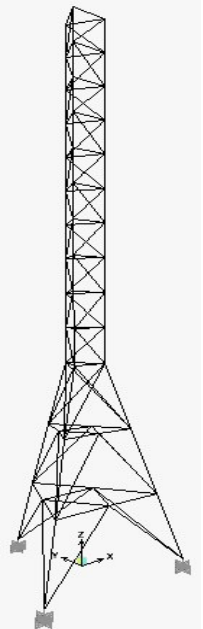

c) TC3

Figure 4. Finite element meshes of the tower models.

Table 2. Geometric properties and natural periods of the modeled towers.

\begin{tabular}{|c|c|c|c|c|c|c|c|}
\hline \multirow[b]{2}{*}{ Tower ID } & \multirow[b]{2}{*}{$\begin{array}{l}\text { Height } \\
\text { (m) }\end{array}$} & \multirow[b]{2}{*}{$\begin{array}{l}\text { Base width } \\
\text { (m) }\end{array}$} & \multirow[b]{2}{*}{$\begin{array}{l}\text { Top width } \\
\text { (m) }\end{array}$} & \multirow[b]{2}{*}{ Mass (kg) } & \multicolumn{3}{|c|}{ Natural periods } \\
\hline & & & & & $\begin{array}{c}\mathrm{T}_{1}(\mathrm{~s}) \\
\text { (flexural) }\end{array}$ & $\begin{array}{c}\mathrm{T}_{2}(\mathrm{~s}) \\
\text { (flexural) }\end{array}$ & $\begin{array}{c}\mathrm{T}_{3}(\mathrm{~s}) \\
\text { (torsion) }\end{array}$ \\
\hline TC1 & 30 & 2.50 & 1.50 & 2245 & 0.37 & 0.37 & 0.11 \\
\hline TC2 & 20 & 2.50 & 1.50 & 1735 & 0.19 & 0.19 & 0.081 \\
\hline TC3 & 20 & 5.50 & 1.30 & 2920 & 0.25 & 0.25 & 0.084 \\
\hline
\end{tabular}




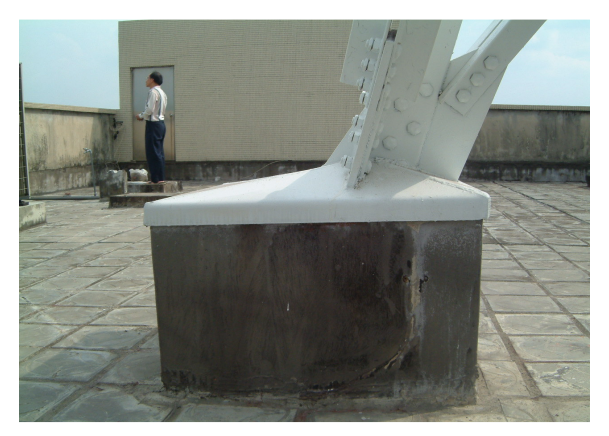

Figure 5. Illustration of tower support at the building-tower interface.

\section{Response to horizontal accelerations}

The proposed simplified method requires the determination of: the input seismic acceleration at the tower base-rooftop level, which is discussed in Assi (2006) and Assi et al. (2005); the mass profile of the tower $\mathrm{m}(\mathrm{x})$ that can be calculated from the tower's structural drawings and attachments (antenna drums, transmission cables, platforms, etc.); and a horizontal acceleration profile $\mathrm{a}(\mathrm{x})$ along the tower's height, I. The concept of the method is illustrated schematically in Fig. 6. The prediction of the tower acceleration profile $a(x)$ is the key factor in this method. It was found that the acceleration amplification profile along a telecommunication tower mounted on a building rooftop matches reasonably well its fundamental mode shape when mounted on a rigid base. Equations 1 and 2 provide the basis for evaluating the base shear force, $V_{\text {base }}$, and the base overturning moment, $M_{\text {base }}$, using the proposed method.

$$
\begin{aligned}
& V_{\text {base }}=\int_{0}^{1} v_{x} d x=\int_{0}^{l} m(x) a(x) d x \\
& M_{\text {base }}=\int_{0}^{1} v_{x} x d x=\int_{0}^{1} m(x) a(x) x d x
\end{aligned}
$$

\section{Prediction of tower acceleration profiles $a(x)$}

In most of the cases studied, a strong correspondence was found between the tower acceleration amplification profile and its fundamental sway mode shape. This correspondence is further discussed in Assi (2006) and illustrated in Figs. 7 and 8 for the TC2 tower mounted on the CHYBA9 Tainan building. The acceleration amplification profiles were calculated for each of the six series of earthquake records applied separately to both principal horizontal directions of the buildings, U1 and U2. Also added to the graphs is the proposed acceleration amplification profile corresponding to the fundamental mode shape of each tower mounted on a rigid base, adjusted to match the maximum acceleration amplification at the tower top. Following this study, adjustment factors were proposed to multiply the tower fundamental mode shape to obtain its acceleration amplification profile when mounted on a stiff building ( $T<0.6 \mathrm{~s})$, as illustrated in Fig. 9 and Table 3 , where $T$ is the fundamental period of the building and $T_{p}$ is the fundamental period of the tower. When the tower is more flexible than the building, the former does not always experience amplification; however, a minimum factor of 1 is suggested to remain conservative. For a tower mounted on a flexible building, it is proposed to multiply its mode shape by a factor of 3 times the rooftop horizontal acceleration in order to obtain the tower acceleration profile. 


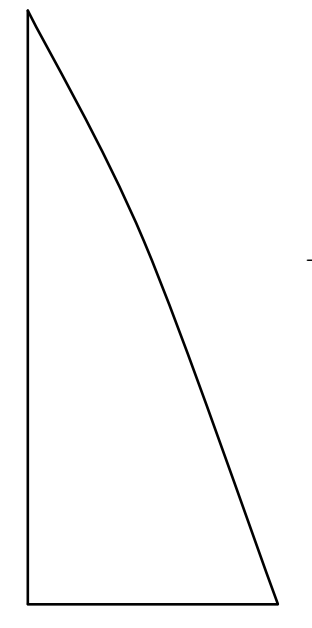

Bending moment distribution from $1^{\text {st }}$ flexural mode

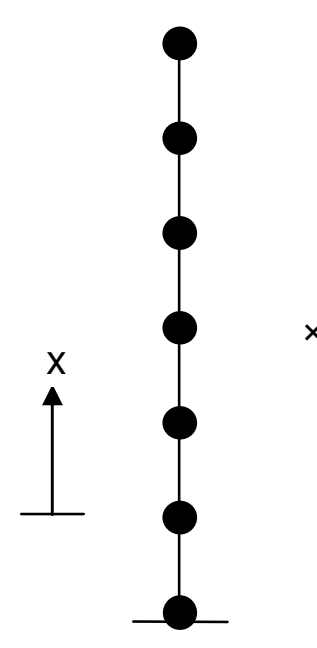

Tower mass distribution $\mathrm{m}(\mathrm{x})$

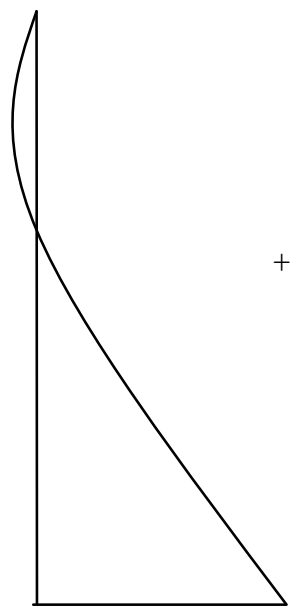

Bending moment distribution from $2^{\text {nd }}$ flexural mode

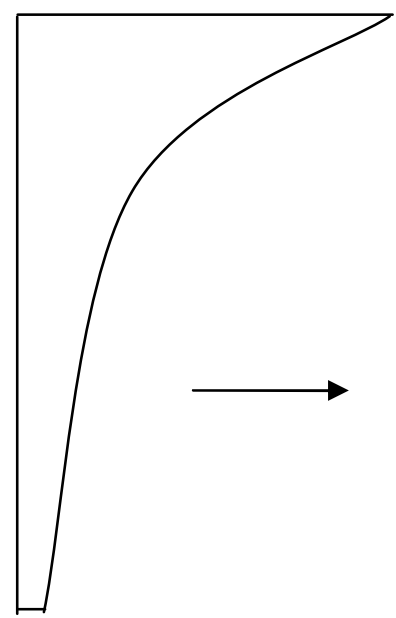

Unknown acceleration amplification profile a $(x)$

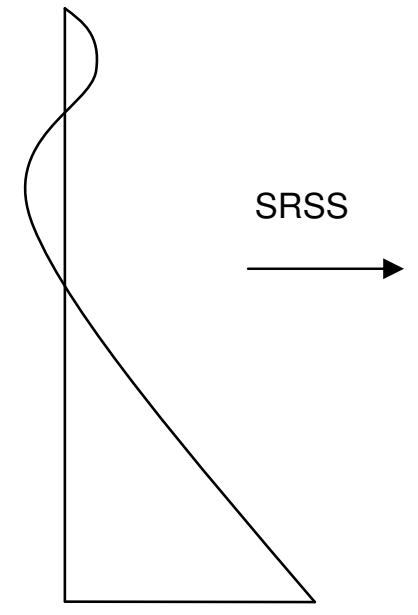

Bending moment distribution from $3^{\text {rd }}$ flexural mode

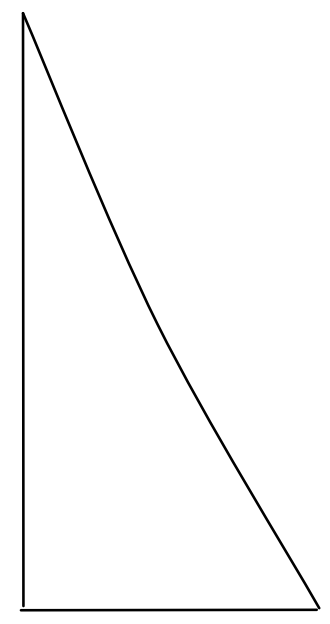

Resultant bending moment distribution using SRSS modal combination $\left(\mathrm{M}_{\mathrm{f}}\right)$

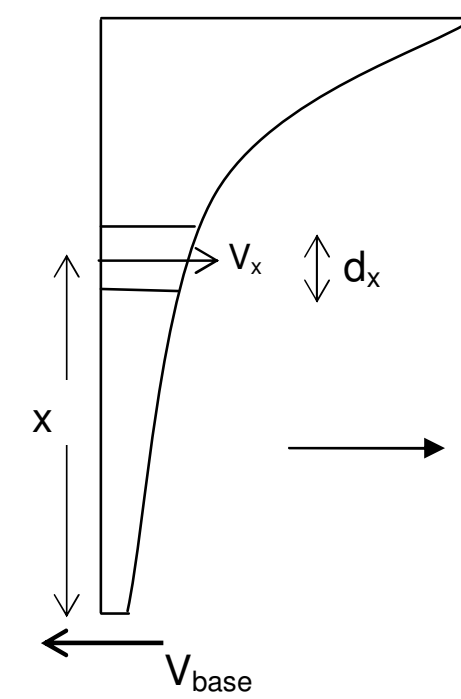

Resultant base shear force using the simplified method

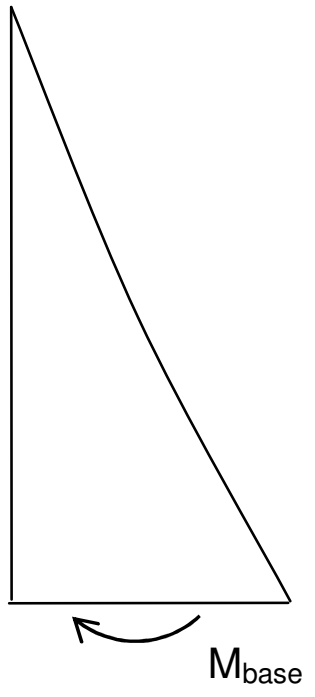

Resultant bending moment using the simplified method

Figure 6. Concept of the proposed method 


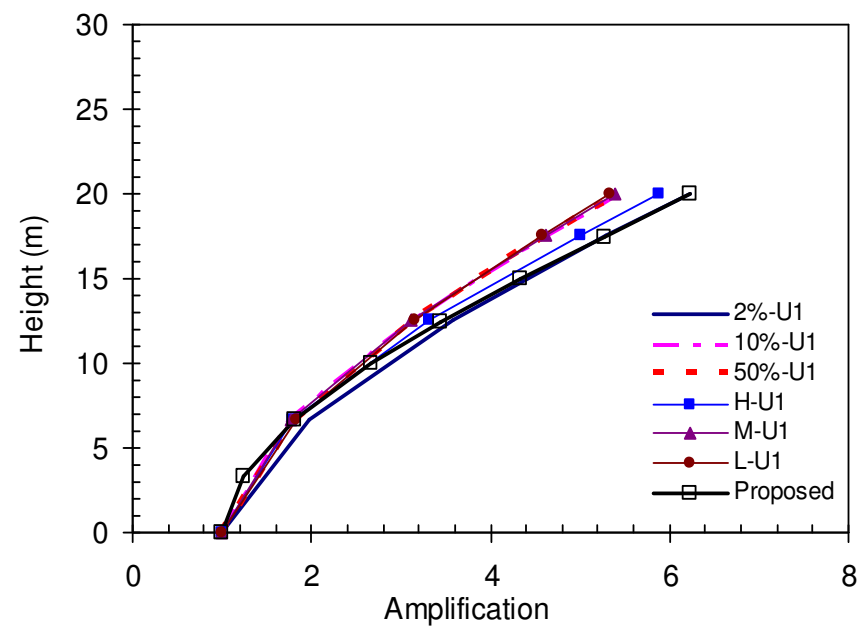

Figure 7. Acceleration amplification profiles of TC2 mounted on CHYBA9 - U1 direction.

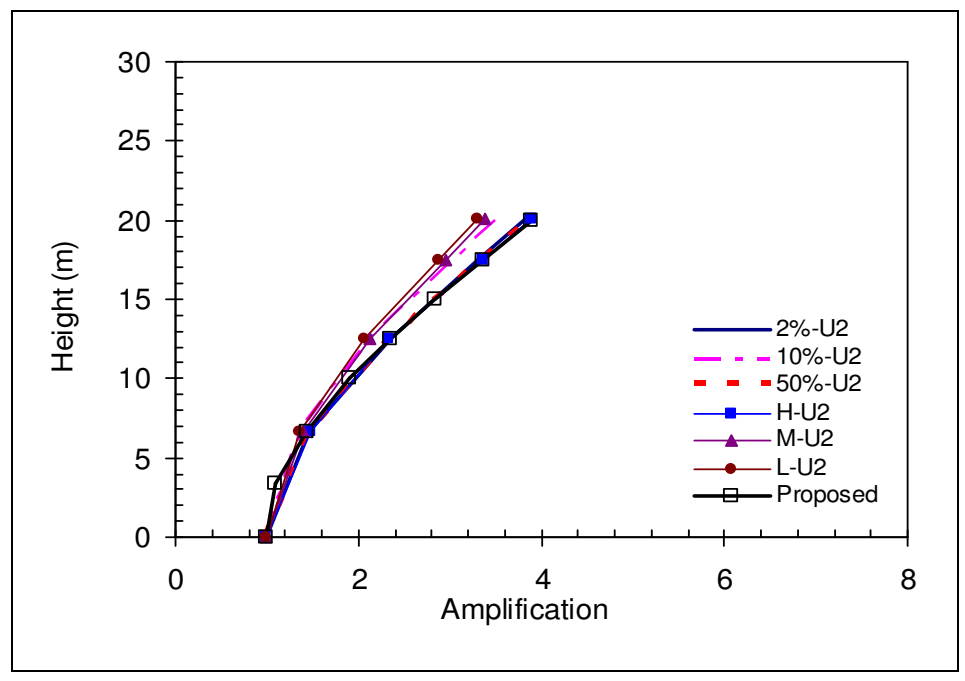

Figure 8. Acceleration amplification profiles of TC2 mounted on CHYBA9 - U2 direction.

Table 3. Proposed tower acceleration amplification factors for stiff buildings $(T<0.6 \mathrm{~s})$.

\begin{tabular}{|c|c|}
\hline $\mathbf{T}_{\mathbf{p}} / \mathbf{T}$ & Factor \\
\hline 0 to 0.6 & 1.0 \\
\hline 0.9 to 1.1 & 4.0 \\
\hline$\geq 1.2$ & 1.0 \\
\hline
\end{tabular}




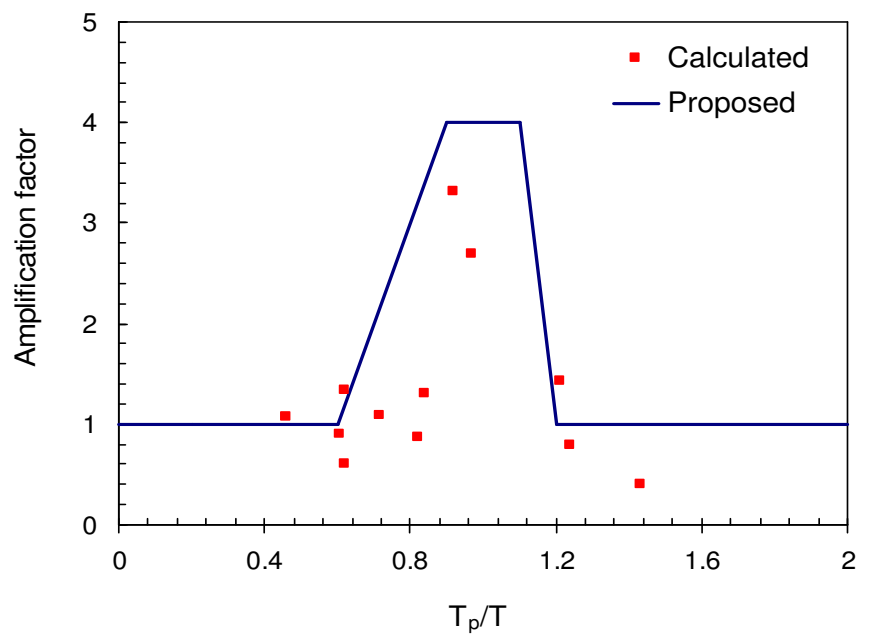

Figure 9. Proposed and calculated tower acceleration amplification factors versus $T_{p} / T$ for stiff buildings $(\mathrm{T}<0.6 \mathrm{~s})$

\section{Parametric study to verify the proposed simplified method}

Using Equations 1 and 2 for each building-tower combination, the values of equivalent base shear forces and overturning moments at the building-tower interfaces were calculated as shown schematically in Fig. 6 . The shear force diagram was obtained by multiplying the mass and the acceleration profiles; the base overturning moment was obtained by integrating the mass profile, the acceleration profile, and the moment arm. Results were compared to the peak values obtained from detailed linear seismic analysis of the Sap models using the SRSS modal combination with the 20 lowest frequency modes and $3 \%$ of critical viscous damping in each mode. The average results for all sets of records are presented in Tables 4 to 6. In these tables, $V$ and $M_{f}$ are the base reactions calculated in the numerical simulations, while $V_{\text {base }}$ and $M_{\text {base }}$ are the base reactions calculated according to the proposed simplified method. $\mu$ and $\sigma$ are the mean value and standard deviation of the results. It is noted that each statistical parameter is based on 74 numerical results.

Table 4. Verification of the simplified method for TC1, TC2, and TC3 mounted on CHYBA9.

\begin{tabular}{|c|c|c|c|c|c|c|c|c|}
\hline \multirow{2}{*}{$\begin{array}{c}\text { CHYBA9 } \\
\text { combined with }\end{array}$} & \multicolumn{4}{|c|}{$\mathbf{M}_{\text {base }} / \mathbf{M}_{\mathbf{f}}$} & \multicolumn{4}{c|}{$\mathrm{V}_{\text {base }} / \mathbf{V}$} \\
\cline { 2 - 9 } & $\mathbf{U 1}$ & \multicolumn{2}{|c|}{ U2 } & \multicolumn{2}{c|}{ U1 } & \multicolumn{2}{c|}{ U2 } \\
\cline { 2 - 9 } & $\boldsymbol{\mu}$ & $\boldsymbol{\sigma}$ & $\boldsymbol{\mu}$ & $\boldsymbol{\sigma}$ & $\boldsymbol{\mu}$ & $\boldsymbol{\sigma}$ & $\boldsymbol{\mu}$ & $\boldsymbol{\sigma}$ \\
\hline TC1 & 1.36 & 0.28 & 1.26 & 0.20 & 1.72 & 0.40 & 1.50 & 0.27 \\
\hline TC2 & 0.98 & 0.08 & 0.98 & 0.08 & 0.97 & 0.07 & 0.99 & 0.08 \\
\hline TC3 & 1.03 & 0.01 & 0.99 & 0.12 & 0.96 & 0.05 & 0.99 & 0.14 \\
\hline
\end{tabular}


Table 5. Verification of the simplified method for TC1, TC2, and TC3 mounted on CHYBA4.

\begin{tabular}{|c|c|c|c|c|c|c|c|c|}
\hline \multirow{2}{*}{$\begin{array}{c}\text { CHYBA4 } \\
\text { combined with }\end{array}$} & \multicolumn{4}{|c|}{$\mathbf{M}_{\text {base }} / \mathbf{M}_{\mathbf{f}}$} & \multicolumn{4}{c|}{$\mathrm{V}_{\text {base }} / \mathbf{V}$} \\
\cline { 2 - 9 } & \multicolumn{2}{|c|}{ U1 } & \multicolumn{2}{|c|}{ U2 } & \multicolumn{2}{c|}{ U1 } & \multicolumn{2}{c|}{ U2 } \\
\cline { 2 - 9 } & $\boldsymbol{\mu}$ & $\boldsymbol{\sigma}$ & $\boldsymbol{\mu}$ & $\boldsymbol{\sigma}$ & $\boldsymbol{\mu}$ & $\boldsymbol{\sigma}$ & $\boldsymbol{\mu}$ & $\boldsymbol{\sigma}$ \\
\hline TC1 & 0.99 & 0.08 & 1.17 & 0.19 & 1.04 & 0.11 & 1.30 & 0.18 \\
\hline TC2 & 0.99 & 0.10 & 0.97 & 0.06 & 1.11 & 0.13 & 1.04 & 0.05 \\
\hline TC3 & 1.08 & 0.25 & 1.04 & 0.05 & 1.12 & 0.20 & 0.94 & 0.08 \\
\hline
\end{tabular}

Table 6. Verification of the simplified method for TC1, TC2, and TC3 mounted on 2020 University.

\begin{tabular}{|c|c|c|c|c|c|c|c|c|}
\hline \multirow{2}{*}{$\begin{array}{c}2020 \\
\text { combined with }\end{array}$} & \multicolumn{4}{|c|}{$\mathbf{M}_{\text {base }} / \mathbf{M}_{\mathbf{f}}$} & \multicolumn{4}{c|}{$\mathbf{V}_{\text {base }} / \mathbf{~}$} \\
\cline { 2 - 9 } & \multicolumn{2}{|c|}{$\mathbf{U 1}$} & \multicolumn{2}{|c|}{ U2 } & \multicolumn{2}{|c|}{ U1 } & \multicolumn{2}{c|}{ U2 } \\
\cline { 2 - 9 } & $\boldsymbol{\mu}$ & $\boldsymbol{\sigma}$ & $\boldsymbol{\mu}$ & $\boldsymbol{\sigma}$ & $\boldsymbol{\mu}$ & $\boldsymbol{\sigma}$ & $\boldsymbol{\mu}$ & $\boldsymbol{\sigma}$ \\
\hline TC1 & 1.04 & 0.08 & 1.60 & 0.54 & 1.14 & 0.08 & 1.39 & 0.26 \\
\hline TC2 & 0.99 & 0.02 & 1.03 & 0.09 & 1.09 & 0.03 & 1.06 & 0.06 \\
\hline TC3 & 1.05 & 0.15 & 1.12 & 0.59 & 1.02 & 0.13 & 1.21 & 0.47 \\
\hline
\end{tabular}

The average ratios $(\mu)$ given in Tables 4 to 6 indicate that the proposed simplified method predicts higher values than the detailed calculation in most cases, so it is conservative. Moreover, the proposed method becomes more accurate as the fundamental period of the tower decreases.

The reasonably small standard deviations obtained for stiff buildings (Tables 4 and 5) between the predictions of the different loading cases for each building-tower combination suggest that the method is suitable regardless of the frequency content of the input seismic excitations. It is also noted that in general the method is slightly more accurate for the calculation of base overturning moments than for the calculation of base shear forces. This was also observed by McClure et al. (2000) in relation to the predicted response of towers founded on ground.

\section{Conclusions}

A simplified analysis method for the evaluation of seismic forces at the base of self-supporting telecommunication towers mounted on rooftops was presented. The proposed method was verified by comparing its predictions to the results of detailed numerical simulations of 9 building-tower combinations subjected to 74 input accelerograms applied to the two main building directions and generated in Sap 2000. It was found that the method generally yields conservative results for the base shear forces and overturning moments, and it is suitable regardless of the frequency content of the input seismic excitations. The method is proposed as a simplified design check: if this design check indicates that seismic loads do govern the tower design, a more detailed dynamic analysis of the tower-building system is recommended. It is further suggested that a detailed dynamic analysis be performed for flexible towers 
mounted on high-rise buildings and for towers supporting heavy attachments, especially in high seismicity zones.

\section{Acknowledgments}

Financial assistance from the Natural Sciences and Research Council (NSERC) of Canada and the Lebanese National Council for Scientific Research (LNCSR) is gratefully acknowledged. We would also like to thank Professor George Yao of the National Cheng Kung University in Tainan City and the Central Weather Bureau in Taiwan (ROC) for providing the instrumented building data. Financial support from the National Science Council in Taiwan (ROC) is also acknowledged.

\section{References}

Assi, R., 2006. A simplified method for seismic analysis of telecommunication towers mounted on building rooftops. PhD thesis, McGill University, Montréal, Canada.

Assi, R., McClure, G., and Yao G.C., 2005. Floor Acceleration demands for 11 instrumented buildings in Taiwan during the 1999 Chi Chi Earthquake. Proceedings of the 2005 Structures Congress, American Society of Civil Engineering, April 20-24, New York, USA.

Atkinson, G., and Beresnev, I., 1998. Compatible ground motion time histories for new national seismic hazard maps, Canadian Journal of Civil Engineering 25 (2), 305-318.

Canadian Standards Association (CSA), 2001. Antennas, towers and antenna-supporting structures, CSA S37-M01, Rexdale, Ontario.

IBC, 2000. International Building Code, International Code Council, Fall Church, Virginia, USA (IBC 2000, NRC/IRC 2005, TIA/EIA 2005)

McClure, G., Lapointe, M., and Khedr M., 2000. Seismic behavior of steel lattice telecommunication towers. Proceedings of the Third International Conference STESSA 2000, F.M. Mazzoanni and R. Tremblay Ed., Montréal, Canada, pp. 335-337.

NRC/IRC, 2005. National Building Code of Canada, National Research Council of Canada, Ottawa, Ontario.

Standards Association of Australia, 1994. AS 3995 (1994) - Design of steel lattice towers and masts, Standards Association of Australia, 1 Crescent, Homebush, New South Wales 2140.

TIA/EIA, 2005. TIA EIA-222-G: Structural standard for antenna supporting structures and antennas, Telecommunication Industry Association, Arlington, VA 22201, USA.

Tso, W.K., Zhu, T.J., and Heidebrecht, A.C., 1992. Engineering implication of ground motion A/V ratio. Soil Dynamics and Earthquake Engineering, 11(3), 133-144.

Wilson, E.L., and Habibullah, A., 2003. SAP 2000 User's manual, Computers and Structures Inc., Berkeley, California, USA. 